\title{
The effect of zinc supplementation on pregnancy outcomes: a double-blind, randomised controlled trial, Egypt
}

\author{
Samia A. Nossier ${ }^{1 *}$, Noha E. Naeim², Nawal A. El-Sayed ${ }^{3}$ and Azza A. Abu Zeid ${ }^{2}$ \\ ${ }^{1}$ Department of Family Health, High Institute of Public Health, Alexandria University, \\ 165 El-Horreya Avenue, El-Hadara, Alexandria, Egypt \\ ${ }^{2}$ Alexandria Regional Center for Women's Health (ARC), Health Directorate, Ministry of Health, Alexandria, Egypt \\ ${ }^{3}$ Department of Nutrition, High Institute of Public Health, Alexandria University, Egypt \\ (Submitted 16 July 2014 - Final revision received 18 March 2015 - Accepted 14 April 2015 - First published online 23 June 2015)
}

\begin{abstract}
The present randomised controlled trial (RCT) was conducted to evaluate the effect of two regimens of $\mathrm{Zn}$ supplementation on pregnancy outcomes in Alexandria, Egypt. Healthy pregnant women aged 20-45 years and having low serum $\mathrm{Zn}$ level below the estimated median for the gestational age were eligible to participate in the trial. Of 1055 pregnant women assessed for the eligibility of low serum $\mathrm{Zn}$ level, 675 were eligible. These women were randomly assigned to one of the three groups: the $Z n$ alone group $(n 225)$ received a daily dose of $30 \mathrm{mg} \mathrm{ZnSO}_{4}$, the combined group ( $n$ 227) received $30 \mathrm{mg} \mathrm{ZnSO}_{4}$ plus multivitamins $\left(\mathrm{B}_{1}, \mathrm{~B}_{6}, \mathrm{D}_{3}, \mathrm{C}\right.$ and $\mathrm{E}$ ) and the control group ( $n$ 223) received placebo $(270 \mathrm{mg}$ lactose). They were followed up from the time of recruitment till 1 week after delivery. Overall, there was no detectable difference in the mean birth weight between the three groups (mean 2929.12 (SD 330.28), 2922.22 (SD 324.05) and 2938.48 (sD 317.39) $\mathrm{g}$ for the placebo, $\mathrm{Zn}$ and $\mathrm{Zn}$ plus multivitamin groups, respectively, $P=0 \cdot 88$ ). Both the single and the combined $\mathrm{Zn}$ supplements were almost equally effective in reducing second- and third-stage complications (relative risk (RR) 0.43, 95\% CI 0.31, 0.60 for the Zn group and RR 0.54, 95\% CI 0.40, 0.73 for the combined group). Stillbirth and preterm delivery were significantly lower among the two supplemented groups than the placebo group $(P=0 \cdot 001)$. Early neonatal morbidity was also significantly lower in the supplemented groups (RR 0.23, $95 \%$ CI 0.15, 0.35 for the Zn group and RR 0.25, $95 \%$ CI 0.16, $0 \cdot 37$ for the combined group). Collectively, Zn supplementation was effective in reducing pregnancy complications and early neonatal infection among the Zn-deficient women of the present trial.
\end{abstract}

Key words: Birth weight: Pregnancy outcome: Micronutrient supplementation: Zinc supplementation: Egypt

In Egypt, pregnant women who attend antenatal care (ANC) services are routinely given $\mathrm{Fe}$ and folic acid supplements but not $\mathrm{Zn}$ supplement. The International Zinc Nutrition Consultative Group Steering Committee estimated that $9 \%$ of the population in Egypt was at a risk of inadequate $\mathrm{Zn}$ intake $^{(1)}$. Meanwhile, the Egyptian Demographic and Health Survey 2008 indicated that $29 \%$ of children under the age of 5 years were stunted ${ }^{(2)}$. Based on the aforementioned two proxy indicators of $\mathrm{Zn}$ deficiency, Egypt had been classified to be in the medium risk category of $\mathrm{Zn}$ deficiency ${ }^{(3)}$.

Adequate $\mathrm{Zn}$ nutrition is necessary for normal pregnancy outcome and child growth, immune function and neurobehavioural development ${ }^{(4)}$. Most observational studies have noted that low serum $\mathrm{Zn}$ levels are linked to prolonged labour and post-partum haemorrhage, pregnancy-induced hypertension, preterm birth and poor perinatal outcome ${ }^{(5-7)}$, while some have shown association with low birth weight
$(\mathrm{LBW})^{(8,9)}$. However, supplementation trials have reported inconsistent findings of the effects of $\mathrm{Zn}$ supplementation. Meta-analyses $^{(10,11)}$ and systematic reviews ${ }^{(12,13)}$ did not reveal significant association between birth weight and $\mathrm{Zn}$ supplementation. In contrast, a systematic review (2012) of twenty independent trials ${ }^{(12)}$ has revealed that $\mathrm{Zn}$ supplementation lowers the risk of preterm birth. Darnton-Hill ${ }^{(14)}$ claimed that the effect of $\mathrm{Zn}$ supplementation on preterm birth may be due to a reduction in the incidence or severity of maternal infections, which is a known risk factor for preterm birth.

Zn deficiency commonly coexists with other micronutrient deficiencies. Similar to other developing countries, many women in Egypt suffer from multiple micronutrient (MM) deficiencies, not just Fe deficiency ${ }^{(15,16)}$. Considerable evidence suggests a role for micronutrients in improving some pregnancy outcomes including birth weight, gestational age at

Abbreviations: ANC, antenatal care; LBW, low birth weight; MM, multiple micronutrients; RCT, randomised controlled trial; RR, relative risk; UNIMMAP, international multiple micronutrient preparation.

*Corresponding author: Professor S. A. Nossier, fax + 203 4288436, email samia_nossier@yahoo.com 
birth, and stillbirths and neonatal morbidity and mortality ${ }^{(17)}$. However, nutrition intervention studies ${ }^{(18-21)}$ have not provided unequivocal evidence of an association between micronutrient intakes and pregnancy outcomes. This was attributed to considerable methodological variation across these studies. Small sample size, study population not representing women at high risk for low micronutrient intakes, and use of non-randomised study design have probably limited the chances of these studies to demonstrate a positive association $^{(22)}$.

A meta-analysis (Kawai et al. $)^{(23)}$ and systematic reviews ${ }^{(22,24)}$ have shown that MM supplementation, compared with control supplementation that was usually Fe plus folic acid in most studies, is effective at reducing the risk of LBW (relative risk (RR) $0.86,95 \%$ CI $0.79,0.93$ ) and small size for gestational age (RR $0.85,95 \%$ CI $0.78,0.93$ ), but no overall effect on preterm birth, stillbirth and maternal or neonatal mortality.

The doses used by supplementation trials vary widely. Most studies have assessed the effect of $\mathrm{Zn}$ against a background of other micronutrient supplements where the dose of $\mathrm{Zn}$ ranged from 5 to $44 \mathrm{mg} / \mathrm{d}^{(10)}$. In contrast, the trials that used the international multiple micronutrient preparation (UNIMMAP) $^{(21)}$ used a dose of $15 \mathrm{mg} \mathrm{Zn}$, which is equivalent to one RDA.

Till now, no attempts were made to deliver $\mathrm{Zn}$ and/or multivitamin supplements in ongoing large-scale programmes in Egypt. However, planning to introduce these micronutrients based on the WHO recommendation to use the UNIMMAP to high-risk groups may take place in the near future. Since the typical Egyptian diet is largely based on plants with high content of $\mathrm{Zn}$ inhibitors, mainly phytic acid ${ }^{(25)}$, higher doses of $\mathrm{Zn}$ may be required to cause a detectable effect on pregnancy outcomes. The present study was designed to determine whether doubling the dose of $\mathrm{Zn}$ in a MM supplement (i.e. to be equivalent to two RDA) and using different doses of $\mathrm{B}_{1}, \mathrm{~B}_{6}, \mathrm{E}, \mathrm{D}_{3}$ and vitamin $\mathrm{C}$ will result in pregnancy outcomes different from those reported by studies using the UNIMMAP preparation (i.e. which contains a dose of $\mathrm{Zn}$ equivalent to one RDA). Meanwhile, we used a three-arm trial design with sufficient power to test in one trial the effects of supplementing $\mathrm{Zn}$ alone compared with combining it with MM on the outcomes of pregnancy. Results would provide useful information to policy makers in making decisions about which type of supplement to be introduced in largescale programmes.

\section{Subjects and methods}

\section{Study design}

A double-blind, placebo-controlled, parallel group, randomised trial was conducted in Alexandria, Egypt, from February 2007 to September 2009. Women with low serum Zn level were eligible for enrolment to the study. Zn-alone supplementation in pregnancy is not feasible since Fe-folic acid supplement is given routinely to women who attend ANC services in Egypt. Accordingly, the effects of Zn supplementation are in fact compared with those of control supplementation with Fe plus folic acid.

Eligible participants ( $n$ 675) were randomly assigned to one of the three parallel groups in 1:1:1 ratio. The control group received placebo, the $\mathrm{Zn}$ group received a daily supplement of $30 \mathrm{mg}$ of $\mathrm{ZnSO}_{4}$ and the combined $\mathrm{Zn}$ plus multivitamin group received $30 \mathrm{mg}$ of $\mathrm{ZnSO}_{4}$ added to multivitamins. We defined 'multivitamins supplement' as a 'single tablet containing more than three micronutrients other than zinc' ${ }^{\text {(24) }}$. The MM supplement used in the present study contains $\mathrm{Zn}$ along with vitamins $\mathrm{B}_{1}, \mathrm{~B}_{6}, \mathrm{D}_{3}, \mathrm{E}$ and $\mathrm{C}$.

\section{Study participants and study settings}

The study population was pregnant women who presented themselves for ANC in two clinics (Smouha and Moharam Bec Maternal and Child Health centres) serving low- and middle-income population in Alexandria, Egypt. Of the 1055 apparently healthy pregnant women aged $20-45$ years assessed for the eligibility of low serum $\mathrm{Zn}$ level, 675 had serum $\mathrm{Zn}$ level below the estimated median for the gestational age. Serum Zn level was measured by using flame atomic absorption spectrophotometry at enrolment and a second measurement was performed between 28 and 32 weeks of gestation.

\section{Eligibility criteria for participants}

The inclusion criteria for the recruitment were gestational age $<16$ weeks assessed by recall of last menstrual period and confirmed by ultrasonography, age range between 20 and 45 years, BMI between 18 and $26 \mathrm{~kg} / \mathrm{m}^{2}$, normal course of pregnancy and $\mathrm{Zn}$ level at the time of enrolment below the estimated median for gestational age $(7 \cdot 5 \mu \mathrm{g})^{(26)}$.

Women were excluded if they were identified through interviews to be on any other form of $\mathrm{Zn}$ supplements at any dosage, were older than 35 years at first pregnancy, had an established risk of having reduced or excessive birth weight of infants (e.g. diabetes, hypertension, and renal and heart disease) and cases that developed complications or had a twin pregnancy during the follow-up period.

\section{Ethical considerations}

The present study was conducted according to the guidelines laid down in the Declaration of Helsinki. Informed consent forms were obtained before enrolment and eligible women were given copies of the signed forms. Each woman was given a unique serial number that was recorded on her antenatal care card. Confidentiality was maintained throughout the experiment. The protocol of the study was approved by the ethics committee of Ministry of Health and the ethics committee of High Institute of Public Health. Permission to carry out the study in the ANC clinics in Alexandria was obtained from the local health authority. The trial was registered in the WHO Pan African Trial Registry after both recruitment and data analysis (PACTR201303000453309). 


\section{The intervention}

The supplements were supplied as a package (box of thirty capsules) every month during the regular ANC visits. Checking the regularity of intake was done every visit. The supplements were taken every day from enrolment till delivery. Capsules were all of the same shape, smell, taste and colour. Boxes of the supplement were labelled by the specific number of the woman. The eligible women receive one of the following regimens: (1) placebo capsule (270 mg lactose); (2) ZnSO 4 capsule (30 mg $\mathrm{Zn}^{2+}$ and $270 \mathrm{mg}$ lactose); (3) multivitamin capsule with $\mathrm{Zn}\left(30 \mathrm{mg} \mathrm{Zn}^{2}\right.$, vitamin $\mathrm{B}_{1}(0 \cdot 13 \mathrm{mg})$, vitamin $\mathrm{B}_{6}$ (1.94 mg), vitamin E (5.73 mg), vitamin $\mathrm{D}_{3}$ (3.1 mg (approximately equal to $309 \mathrm{IU})$ ), vitamin $\mathrm{C}(66.5 \mathrm{mg})$ and $270 \mathrm{mg}$ lactose).

All recruited women were screened for eligibility. They were subjected to initial assessment that includes the following:

(1) Collection of sociodemographic and obstetric data: the trial physician used a predesigned questionnaire to collect the following:

(a) Personal and sociodemographic data such as age, residence and educational level (including the following categories: read and write or illiterate, primary, preparatory, secondary and university level or higher); working status (unskilled, skilled, clerical, professional and not working); family size (two persons, three, four, five and six persons, or more); and income (always in debt, sometimes in debt, just sufficient and saving).

(b) Obstetric data such as gravidity, parity, abortions and obstetric complications in previous pregnancies or deliveries.

(2) Anthropometric measurements: weight was measured to the nearest $0 \cdot 1 \mathrm{~kg}$ on an electronic bathroom weighing scale and height was measured to the nearest $0 \cdot 1 \mathrm{~cm}$ with a height stick. BMI was calculated as follows: BMI = weight in $\mathrm{kg}$ /height in $\mathrm{m}^{2}$.

(3) Determination of gestational age: gestational age was determined using the last menstrual period. Ultrasound was used for the verification of gestational age for all cases. The dates for the assessment of gestational age at recruitment and at delivery were all recorded in the data collection form. The length of gestation was subsequently calculated in completed weeks from the recorded data.

(4) Routine examination: it included blood pressure measurement, chest and heart examination, fundal level examination and checking for lower limb oedema.

(5) Routine laboratory investigations: it included urine analysis, random blood glucose level and measurement of $\mathrm{Hb}$ concentration using the cyanmethaemoglobin method.

After this initial assessment, women ( $n$ 1055) were tested for eligibility in terms of Zn deficiency.
(1) Determination of serum zinc: non-fasting venous blood was collected during morning hours for the determination of serum $\mathrm{Zn}$ level by using plastic syringes, stainless steel needles and trace mineral-free plastic tubes. Serum was separated at a maximum of $6 \mathrm{~h}$ after collection and stored at $-20^{\circ} \mathrm{C}$ until analysed. Zn concentration was measured by using flame atomic absorption spectrophotometry. The reference median serum $\mathrm{Zn}$ level at each gestational age was based on the values obtained from a study on pregnant women attending maternal and child health centres in Alexandria ${ }^{(26)}$.

(2) Assessment of dietary intake: dietary intake was measured by using $24 \mathrm{~h}$ recall method and a FFQ, focussing on the intake of foods that might enhance or inhibit $\mathrm{Zn}$ absorption. This assessment was done on a subsample of 100 women in the three studied groups. Enhancers of $\mathrm{Zn}$ absorption were enquired about their protein intake and low $\mathrm{Ca}$ intake represented in low consumption of dairy products. Inhibitors of $\mathrm{Zn}$ absorption were represented in fibres, phytates and Fe. The nutritive value of the daily diet was computed using the Egyptian food composition tables $^{(27)}$. The mean daily intake was compared with that of the recommended dietary intake level of the Food and Nutrition Board, Institute of Medicine ${ }^{(28)}$, to get the per cent adequacy of intake from the specified nutrient.

Those having $\mathrm{Zn}$ deficiency ( $n$ 675) were randomised into the three trial groups. During the monthly follow-up, the trial physician carried out the following:

(1) Routine antenatal examination.

(2) The second measurement of serum $\mathrm{Zn}$ : a second blood sample was taken between 28 and 32 weeks of gestation.

(3) Anthropometry of women: weight gain was measured monthly. Total weight gain defined as: weight at last visit before delivery - weight at enrolment was measured and compared with the recommended total weight gain in pregnant women by pre-pregnancy BMI (in $\left.\mathrm{kg} / \mathrm{m}^{2}\right)^{(29)}$. Ultrasound examination to all women was performed at 24-34th week of gestation and as indicated to assess the gestational age and the anthropometric measurements of the fetus.

(4) Post-partum data: data on delivery, postnatal complications, birth weight and neonatal complications were obtained by a trained nurse/midwife during the postpartum home visits and also during the routine first visit of the newborn to the health facility for immunisation and thyroid blood sample testing (first week after delivery).

\section{Outcome measures}

\section{Primary outcome measures}

(1) Birth weight was measured within $72 \mathrm{~h}$ of birth to the nearest $10 \mathrm{~g}$.

(2) Delivery data included mode of delivery, second- and third-stage complications, stillbirth and preterm delivery.

(3) Neonatal data included head, chest and arm circumferences to the nearest $0 \cdot 1 \mathrm{~cm}$, clinically apparent congenital 
malformation and early neonatal morbidity, mainly infections. Neonatal infection was ascertained on the basis of either maternal report of a specific severe respiratory sign such as distress or report of respiratory diseaserelated hospitalisations.

Secondary outcome measures. These included serum $\mathrm{Zn}$ after supplementation and total weight gain.

\section{Sample size}

The sample size required to enable detection of a mean difference of $150 \mathrm{~g}$ in birth weight with $80 \%$ power, $0.5 \mathrm{sD}$ for each group, $5 \%$ level of significance was estimated to be 534 ( $n 178$ each group). The study included up to 675 cases to compensate for the potential exclusion after randomisation and loss to follow-up. So, after randomisation of participants ( $n$ 675) to the different groups, there were 223 cases in the placebo group, 225 cases in the $\mathrm{Zn}$ group and 227 cases in the combined $\mathrm{Zn}$ and multivitamin group.

\section{Randomisation}

Participants were randomly assigned to one of the three study groups. An independent statistician generated the allocation sequence using computer-generated random numbers, using Excel software. After obtaining informed consent for enrolment, the investigators randomly assigned participants till the required sample size was met. There was no stratification during the randomisation.

\section{Concealment of random allocation sequence}

The assignment of participants to study conditions was carried out at the study centres. A co-worker wrote the treatment allocations (A, B and C) on sequentially numbered opaque plastic boxes. One box containing thirty capsules of a given random number was prepared for monthly use. Thus, five boxes were totally numbered for each participant. Additional packs were available for non-compliant or replaced cases. The assigned box number was transferred to a folder prepared for each woman where data such as any complications/withdrawal/ non-compliance were recorded. Two copies of randomisation lists were prepared and kept by two independent staff not involved in the study. They kept them until collection and analysis of data were completed. Deciphering of group labels took place after completing the analysis and commenting on the results.

\section{Blinding}

The supplements were supplied by a local pharmaceutical company (Pharo Pharma). The capsules were of the same shape, colour and taste. All study personnel - except the statistician who generated the sequence - and the participants were blinded to the allocation.

\section{Administration of supplements and monitoring of compliance}

Each participant was supplied with enough supplements to last for 1 month at a time. Participant was instructed to take one capsule daily after meals and to bring the boxes of the supplement during each follow-up visit to check the regularity of intake. Compliance was monitored by pill counting. Compliance was considered adequate when it exceeds $90 \%$ of total intake during the trial period.

\section{Data collection and data management}

A pilot study was conducted on thirty women. The questionnaire was completed in about $20-30 \mathrm{~min}$. Some dietary data were added and the questionnaire was put in its final form.

\section{Statistical analysis}

Data was analysed using the Predictive Analytics Software (PASW Statistics 18). Intention-to-treat strategy was used for primary analysis, and involved all participants who were randomly assigned. Association between categorical variables was tested using $\chi^{2}$ test. Yate's exact correction was applied when more than $20 \%$ of the cells have expected count less than 5. Quantitative data were described using means and standard deviations. When there were $\geq 30$ observations per group, parametric statistics were used for comparing means in the study with disregard to the state of normality of the data as the conclusions drawn by both the $t$ and $F$ distributions will not be seriously affected. Independent one-way ANOVA was used to compare quantitative variables among more than two groups. Paired $t$ test was used for comparing the quantitative variables before and after the intervention. The RR and a 95\% CI were calculated to compare the proportions of cases having a negative outcome in the different groups relative to the control group. The effect size was determined using the RR, absolute risk reduction and numbers needed to treat.

\section{Results}

Fig. 1 shows the flow chart of participants: of the 1450 healthy pregnant women aged 20-45 years assessed for eligibility, 395 cases were excluded. Of the remaining 1055 women, 675 had low serum Zn level and were enrolled. During the follow-up period, thirteen participants developed complications such as diabetes and hypertension and were excluded at different times. Also, sixty-four women lost to follow up (9.48\%) due to different reasons such as lack of tolerance to the supplement (some women disliked the smell of the supplement, others disliked the capsule size and some women could not adhere to daily intake), development of side effects such as nausea or vomiting and desire of some women to deliver at their home villages. Finally, 597 women completed the study (199 cases in the placebo group, 198 in the $\mathrm{Zn}$ group and 200 in the $\mathrm{Zn}$ plus multivitamin group). 
The number of women who completed the study in each group was higher than the minimum sample size required to detect a $150 \mathrm{~g}$ mean birth-weight difference at $80 \%$ power. There were no differences in the compliance levels between the three groups. Women in all groups consumed $>90 \%$ of the supplements provided, and few reported adverse effects such as vomiting, diarrhoea and abdominal pain (see online Supplementary Table S1). Also, characteristics of the women lost to follow-up were not different from participants who continued the trial.

Table 1 presents the baseline demographic and clinical characteristics for each group. The mean age of the study participants at recruitment was 26.54 (SD 4.42), 26.56 (SD 4.45) and 27.90 (SD 4.76) years for placebo, $\mathrm{Zn}$ and $\mathrm{Zn}$ plus multivitamin groups, respectively. The mean gestational age at recruitment was $15 \cdot 10$ (SD 1.41), 15.22 (SD 1.37) and 15.44 (SD 1.09) weeks for the three groups, respectively. The study groups did not differ significantly in terms of their baseline characteristics, except for gestational age where the combined $\mathrm{Zn}$ and multivitamin group had later age at enrolment $(P=0.017)$ and the serum $\mathrm{Zn}$ level as the $\mathrm{Zn}$ group entered the trial with a significantly lower level than the other groups $(P=0 \cdot 025)$.

Table 2 presents the change in total mean weight gain and the serum $\mathrm{Zn}$ level in the three studied groups. The total weight gain of the combined $\mathrm{Zn}$ plus multivitamin group was significantly higher than that of the placebo and $\mathrm{Zn}$ groups $(P<0 \cdot 001)$. In the second testing, the mean $\mathrm{Zn}$ level of the $\mathrm{Zn}$ group was significantly higher than that of the placebo group and the $\mathrm{Zn}$ plus multivitamin group $(P<0 \cdot 001)$. For all the three groups, the second serum $\mathrm{Zn}$ level was significantly higher than the first one $\left(F_{\text {within }}=864.64\right.$; $P<0.001)$. It increased, yet differently, among the three groups $\left(F_{\text {interaction }}=222.21 ; \quad P<0.001\right)$. The change was highest among the $\mathrm{Zn}$ group (mean difference $16.52 \mu \mathrm{g} / \mathrm{dl}$ ) and of less magnitude in the combined $\mathrm{Zn}$ plus multivitamin

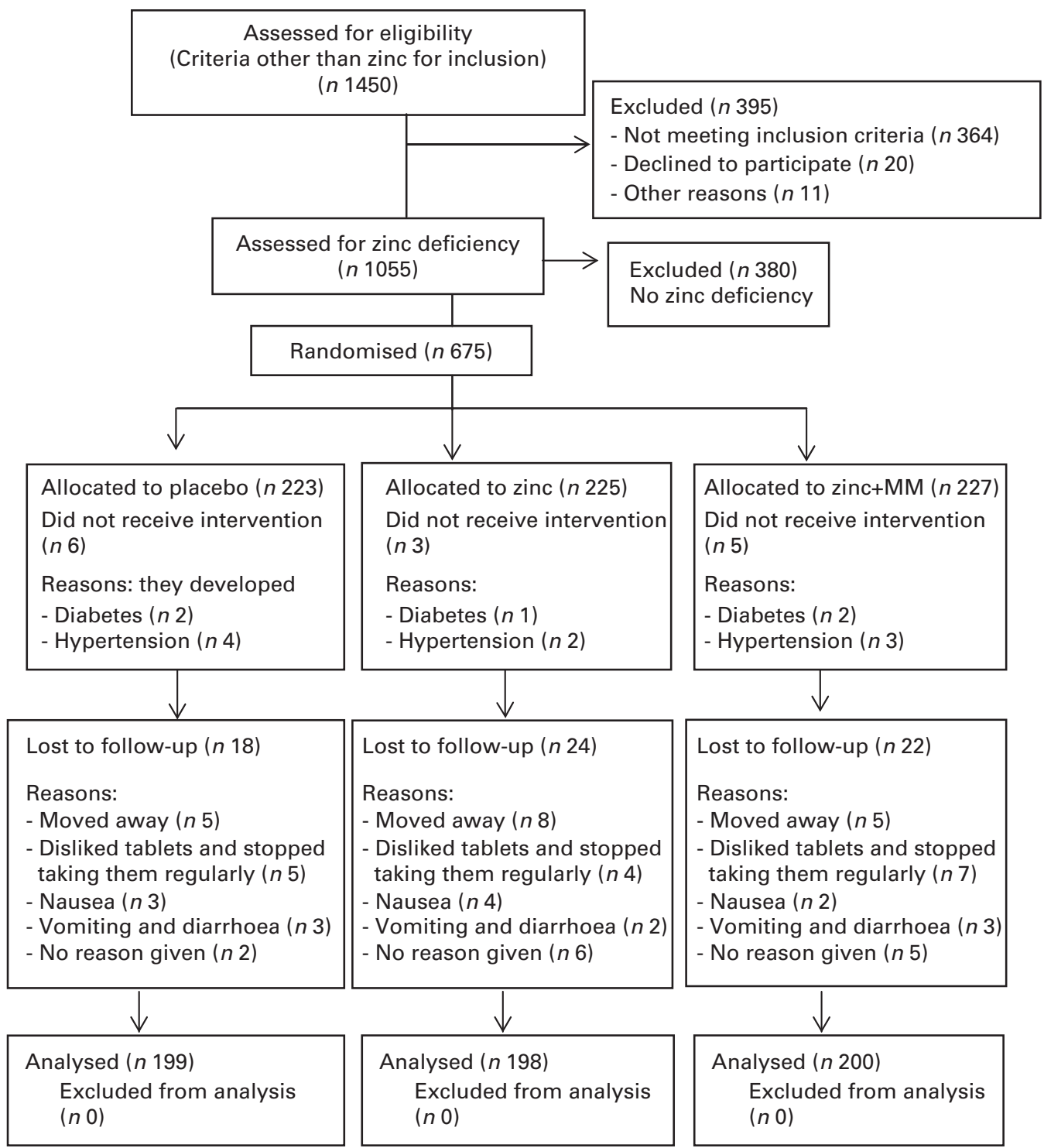

Fig. 1. Flow chart of participants of the randomised controlled trial. MM, multiple micronutrients. 
Table 1. Baseline sociodemographic and clinical characteristics of the three groups of the trial, Alexandria, Egypt

(Mean values and standard deviations, numbers of participants and percentages)

\begin{tabular}{|c|c|c|c|c|c|c|c|c|c|}
\hline \multirow[b]{2}{*}{ Sociodemographic data } & \multicolumn{2}{|c|}{$\begin{array}{l}\text { Placebo group } \\
\qquad(n 223)\end{array}$} & \multicolumn{2}{|c|}{$\begin{array}{l}\text { Zinc group } \\
\quad(n 225)\end{array}$} & \multicolumn{2}{|c|}{$\begin{array}{l}\text { Zinc plus multivita- } \\
\text { min group ( } n 227)\end{array}$} & \multicolumn{3}{|c|}{ Test of significance } \\
\hline & $n$ & $\%$ & $n$ & $\%$ & $n$ & $\%$ & $x^{2}$ & $F$ & $P$ \\
\hline \multicolumn{10}{|l|}{ Age (years) } \\
\hline$<25$ & 81 & $36 \cdot 3$ & 77 & $34 \cdot 2$ & 60 & $26 \cdot 4$ & $15 \cdot 202$ & & 0.055 \\
\hline $25-30$ & 98 & 43.9 & 111 & $49 \cdot 3$ & 106 & $46 \cdot 7$ & & & \\
\hline$\geq 30$ & 44 & $19 \cdot 7$ & 37 & $16 \cdot 4$ & 61 & 26.9 & & & \\
\hline Range & \multirow{2}{*}{\multicolumn{2}{|c|}{$\begin{array}{c}20 \cdot 00-38.00 \\
26.54\end{array}$}} & \multicolumn{2}{|c|}{$20 \cdot 00-38.00$} & \multicolumn{2}{|c|}{$20 \cdot 00-39 \cdot 00$} & & $6 \cdot 609$ & $0.001^{*}$ \\
\hline Mean & & & \multicolumn{2}{|c|}{$26 \cdot 56$} & \multicolumn{2}{|c|}{27.90} & & & \\
\hline SD & \multicolumn{2}{|c|}{4.42} & & & & & & & \\
\hline \multicolumn{7}{|l|}{ Education } & $12 \cdot 809$ & & 0.0119 \\
\hline Read and write or illiterate & 98 & 43.9 & 111 & $49 \cdot 3$ & 106 & $46 \cdot 7$ & & & \\
\hline Primary/preparatory education & 44 & $19 \cdot 7$ & 37 & $16 \cdot 4$ & 61 & $26 \cdot 9$ & & & \\
\hline Secondary education & 79 & $35 \cdot 4$ & 84 & $37 \cdot 3$ & 77 & 33.9 & & & \\
\hline University or higher & 4 & $1 \cdot 8$ & 4 & $1 \cdot 8$ & 3 & $1 \cdot 3$ & & & \\
\hline \multicolumn{7}{|l|}{ Occupation of the women } & $4 \cdot 834$ & & 0.775 \\
\hline Working & 109 & $17 \cdot 5$ & 37 & $16 \cdot 4$ & 32 & $17 \cdot 9$ & & & \\
\hline Not working & 184 & 82.5 & 188 & $83 \cdot 6$ & 184 & $81 \cdot 1$ & & & \\
\hline \multicolumn{7}{|l|}{ Ultrasound gestational age } & & 4.092 & $0.017^{*}$ \\
\hline Mean & \multicolumn{2}{|c|}{$15 \cdot 47$} & \multicolumn{2}{|c|}{$15 \cdot 55$} & \multicolumn{2}{|c|}{$15 \cdot 73$} & & & \\
\hline SD & \multicolumn{2}{|c|}{$1 \cdot 13$} & \multicolumn{2}{|c|}{1.05} & \multicolumn{2}{|c|}{0.79} & & & \\
\hline Number of previous deliveries & & & & & & & $5.057 \dagger$ & & \\
\hline 1 & 176 & 74.9 & 188 & $83 \cdot 6$ & 179 & 78.9 & & & \\
\hline $2-3$ & 54 & $24 \cdot 2$ & 37 & $16 \cdot 4$ & 48 & $21 \cdot 1$ & & & \\
\hline $4+$ & 2 & 0.9 & 0 & 0.0 & 0 & 0.0 & & & \\
\hline Number of abortions & & & & & & & $2.885 \dagger$ & & \\
\hline$<1$ & 221 & $99 \cdot 1$ & 224 & $99 \cdot 6$ & 221 & $97 \cdot 4$ & & & \\
\hline 2 & 2 & 0.9 & 1 & 0.4 & 6 & $2 \cdot 6$ & & & \\
\hline Number of stillbirths & & & & & & & $0.25 \dagger$ & & \\
\hline 0 & 223 & $100 \cdot 0$ & 224 & $99 \cdot 6$ & 227 & $100 \cdot 0$ & & & \\
\hline 1 & 0 & 0.0 & 1 & 0.4 & 0 & 0.0 & & & \\
\hline BMI $\left(\mathrm{kg} / \mathrm{m}^{2}\right)$ & & & & & & & $11 \cdot 125$ & & 0.085 \\
\hline$<22$ & 40 & $17 \cdot 9$ & 43 & $19 \cdot 1$ & 35 & $15 \cdot 4$ & & & \\
\hline $22-24$ & 61 & $27 \cdot 4$ & 37 & $16 \cdot 42$ & 45 & $19 \cdot 8$ & & & \\
\hline $24-<26$ & 81 & $36 \cdot 3$ & 95 & $42 \cdot 2$ & 89 & $39 \cdot 2$ & & & \\
\hline$\geq 26$ & 41 & $18 \cdot 4$ & 50 & $22 \cdot 2$ & 58 & $25 \cdot 6$ & & & \\
\hline Range & 19 & $6 \cdot 81$ & 17 & $6 \cdot 49$ & 19 & 95 & & $2 \cdot 488$ & 0.084 \\
\hline Mean & & & & & & & & & \\
\hline SD & & & & & & & & & \\
\hline Serum Zn (first) ( $\mu \mathrm{g} / \mathrm{dl})$ & & & & & & & & 3.700 & $0.025^{*}$ \\
\hline Mean & & & & & & & & & \\
\hline SD & & & & & & & & & \\
\hline $\mathrm{Hb}(\mathrm{g} / \mathrm{l})$ & & & & & & & $3 \cdot 16$ & & 0.206 \\
\hline$<100$ & 58 & $26 \cdot 0$ & 64 & $28 \cdot 4$ & 76 & 33.5 & & & \\
\hline $100+$ & 165 & $74 \cdot 0$ & 161 & $71 \cdot 6$ & 151 & $66 \cdot 5$ & & & \\
\hline Mean & & & & & & & & 2.990 & 0.051 \\
\hline SD & & & & & & & & & \\
\hline
\end{tabular}

${ }^{\star} P<0.05$.

†Yates' $\chi^{2}$.

group (mean difference $11 \cdot 18 \mu \mathrm{g} / \mathrm{dl}$ ) compared with the mean of 60.68 (sD 9.48) $\mu \mathrm{g} / \mathrm{dl}$ among the placebo group.

Table 3 presents the occurrence of delivery complications, stillbirth and preterm births among the three groups. Differences in the mode of delivery among the three groups were not statistically significant $(P=0.58)$. The group supplemented by both $\mathrm{Zn}$ and multivitamins was less likely to be delivered by caesarean section (RR $0.779,95 \%$ CI $0.562,1.081$ ) than the $\mathrm{Zn}$ supplemented one (RR 0.889, 95\% CI 0.649, 1.214). Prolonged labour was the most apparent complication. The risk of prolonged labour was lower among the $\mathrm{Zn}$ group (RR 0.434 , $95 \%$ CI $0.313,0.601)$ than among the combined group of $\mathrm{Zn}$ plus multivitamins (RR 0.54395\% CI 0.405, 0.727).
Preterm delivery was significantly higher among the placebo group than among the $\mathrm{Zn}$ and combined groups (21 (10.6\%), compared with 2 (1\%) and 4 (2\%), respectively). Cases of $\mathrm{Zn}$ group were less likely to experience preterm labour and stillbirth by about $88 \%$ (RR 0.012, 95\% CI 0.036, 0.377) and cases of $\mathrm{Zn}$ plus multivitamins by $73 \%$ (RR $0 \cdot 268$, 95\% CI $0 \cdot 119$, 0.603) compared with placebo group (Table 3).

The anthropometric measurements and early morbidity of the neonates are presented in Table 4. The birth weight ranged between 2150 and $4000 \mathrm{~g}$ with a mean of 2929.12 (SD 330.28), 2922.22 (SD 324.05) and 2938.48 (SD 317.39) g for the placebo, $\mathrm{Zn}$ and $\mathrm{Zn}$ plus multivitamin groups, respectively. Although the mean weight of babies of the 
Table 2. Comparison between the mean total weight gain and serum zinc level among pregnant women of the three groups using mixed ANOVA test ${ }^{\star}$

(Mean values and standard deviations)

\begin{tabular}{|c|c|c|c|c|c|c|}
\hline \multirow[b]{2}{*}{ Weight gain and serum zinc level } & \multicolumn{2}{|c|}{ Placebo } & \multicolumn{2}{|c|}{ Zinc } & \multicolumn{2}{|c|}{$\begin{array}{c}\text { Zinc plus } \\
\text { multivitamins }\end{array}$} \\
\hline & Mean & SD & Mean & SD & Mean & SD \\
\hline Total weight gain $\dagger(\mathrm{kg})$ & 8.24 & $1 \cdot 14$ & 8.73 & $1 \cdot 15$ & 8.78 & 1.05 \\
\hline Serum Zn first $¥(\mu \mathrm{g} / \mathrm{dl})$ & $60 \cdot 23$ & 6.49 & 58.55 & 6.87 & 59.17 & 6.46 \\
\hline Serum Zn second§ $(\mu \mathrm{g} / \mathrm{dl})$ & $60 \cdot 68$ & 9.48 & $75 \cdot 07$ & 7.44 & $70 \cdot 35$ & 7.95 \\
\hline
\end{tabular}

*Post hoc significant at $(P<0.05)$.

† ANOVA for total weight gain $=14.315(P<0.001)$

$\ddagger$ ANOVA for first serum zinc $=3.700(P=0.025)$

$\S$ ANOVA for second serum zinc $=154.405,(P<0.001)$

combined group was higher than that of the other groups, the difference was not statistically significant $(P=0 \cdot 88$; Table 4$)$. There were also no statistically significant differences between the groups regarding head circumference $(P=0.28)$, chest circumference $(P=0.51)$ and arm circumference $(P=0.58)$.

Difference between the study groups regarding early neonatal morbidity was statistically significant $(P=0 \cdot 001)$. Participants of the Zn-supplemented group were less prone to the occurrence of early neonatal morbidity by 0.225 times (95\% CI $0 \cdot 146$,
0.346) than those of the placebo group, and participants of the multivitamin-supplemented group were less prone to the occurrence of early neonatal morbidity by about $0 \cdot 246$ times (95\% CI $0 \cdot 163,0 \cdot 372)$ than those of the placebo group.

\section{Discussion}

The present randomised controlled trial (RCT) examined the effects of maternal supplementation with two regimens of

Table 3. Delivery data of women of the three groups regarding mode of delivery, second- and third-stage complications, stillbirth and preterm delivery (Numbers of participants and percentages, relative risk (RR) and $95 \%$ confidence intervals)

\begin{tabular}{|c|c|c|c|c|c|c|c|c|c|c|}
\hline \multirow[b]{2}{*}{ Delivery data } & \multicolumn{2}{|c|}{$\begin{array}{c}\text { Placebo } \\
(n \text { 199) }\end{array}$} & \multicolumn{2}{|c|}{ Zinc (n 198) } & \multicolumn{2}{|c|}{$\begin{array}{l}\text { Zinc plus } \\
\text { multivitamins } \\
(n 200)\end{array}$} & \multicolumn{2}{|c|}{ Total } & \multicolumn{2}{|c|}{ Test } \\
\hline & $n$ & $\%$ & $n$ & $\%$ & $n$ & $\%$ & $n$ & $\%$ & Yates' $\chi^{2}$ & $P$ \\
\hline Mode of delivery & & & & & & & & & $2 \cdot 86$ & 0.581 \\
\hline Normal & 139 & $69 \cdot 8$ & 145 & $73 \cdot 2$ & 153 & $76 \cdot 5$ & 437 & $73 \cdot 2$ & & \\
\hline Abnormal & 60 & $30 \cdot 2$ & 53 & $26 \cdot 8$ & 47 & $23 \cdot 5$ & 160 & $26 \cdot 8$ & & \\
\hline $\mathrm{RR}$ & & & \multicolumn{2}{|c|}{0.889} & \multicolumn{2}{|c|}{0.779} & & & & \\
\hline $95 \% \mathrm{Cl}$ & & & \multicolumn{2}{|c|}{$0.649,1.214$} & \multicolumn{2}{|c|}{$0.562,1.081$} & & & & \\
\hline Second- and third-stage complications & & & & & & & & & $43 \cdot 85$ & $<0.001^{*}$ \\
\hline 0 & 111 & $55 \cdot 8$ & 160 & $80 \cdot 8$ & 152 & $76 \cdot 0$ & 423 & 70.9 & & \\
\hline Prolonged labour & 43 & $21 \cdot 6$ & 33 & $16 \cdot 7$ & 28 & $14 \cdot 0$ & 104 & $17 \cdot 4$ & & \\
\hline Obstructed labour & 7 & 3.5 & 0 & 0 & 1 & 0.5 & 8 & $1 \cdot 3$ & & \\
\hline Haemorrhage & 31 & $15 \cdot 6$ & 4 & $2 \cdot 0$ & 17 & $8 \cdot 5$ & 52 & $8 \cdot 7$ & & \\
\hline Others & 7 & 3.5 & 1 & 0.5 & 2 & $1 \cdot 0$ & 10 & $1 \cdot 7$ & & \\
\hline No complication & 111 & $55 \cdot 8$ & 160 & $80 \cdot 8$ & 152 & $76 \cdot 0$ & 423 & $70 \cdot 9$ & & \\
\hline Any complication & 112 & $44 \cdot 2$ & 38 & $19 \cdot 2$ & 48 & $24 \cdot 0$ & 174 & $29 \cdot 1$ & & \\
\hline $\mathrm{RR}$ & & & \multicolumn{2}{|c|}{0.434} & \multicolumn{2}{|c|}{0.543} & & & & \\
\hline $95 \% \mathrm{Cl}$ & & & \multicolumn{2}{|c|}{$0.313,0.601$} & \multicolumn{2}{|c|}{$0.405,0.727$} & & & & \\
\hline ARR & & & \multicolumn{2}{|c|}{0.25} & \multicolumn{2}{|c|}{0.20} & & & & \\
\hline $95 \% \mathrm{Cl}$ & & & \multicolumn{2}{|c|}{$0.16,0.34$} & \multicolumn{2}{|c|}{$0.11,0.29$} & & & & \\
\hline NNT & & & \multicolumn{2}{|c|}{4} & \multicolumn{2}{|c|}{5} & & & & \\
\hline $95 \% \mathrm{Cl}$ & & & \multicolumn{2}{|c|}{6,3} & \multicolumn{2}{|c|}{3,9} & & & & \\
\hline \multicolumn{3}{|l|}{ Stillbirth/preterm } & & & & & & & $24 \cdot 66$ & $<0.001^{*}$ \\
\hline None & 173 & 86.9 & 195 & $98 \cdot 5$ & 193 & $96 \cdot 5$ & 561 & 94.0 & & \\
\hline Stillbirth & 5 & 2.5 & 1 & 0.5 & 3 & 1.5 & 9 & 1.5 & & \\
\hline Preterm labour & 21 & $10 \cdot 6$ & 2 & $1 \cdot 0$ & 4 & $2 \cdot 0$ & 27 & 4.5 & & \\
\hline $\mathrm{RR} \dagger$ & & & \multicolumn{2}{|c|}{0.116} & \multicolumn{2}{|c|}{$0 \cdot 268$} & & & & \\
\hline $95 \% \mathrm{Cl}$ & & & \multicolumn{2}{|c|}{$0.036,0.377$} & \multicolumn{2}{|c|}{$0.119,0.603$} & & & & \\
\hline ARR & & & \multicolumn{2}{|c|}{0.12} & & & & & & \\
\hline $95 \% \mathrm{Cl}$ & & & 0.0 & 0.17 & & & & & & \\
\hline NNT & & & & & & & & & & \\
\hline $95 \% \mathrm{Cl}$ & & & & & & & & & & \\
\hline
\end{tabular}

ARR, absolute risk ratio; NNT, numbers needed to treat.

${ }^{*} P<0.05$.

† RR was calculated as normal $v$. abnormal (preterm and stillbirth). 
Table 4. Anthropometric measurements and early morbidity of the neonates of the three groups of the trial† (Mean values, standard deviations, numbers of participants, percentages, relative risk (RR) and $95 \%$ confidence intervals)

\begin{tabular}{|c|c|c|c|c|c|c|}
\hline \multirow{3}{*}{$\begin{array}{l}\text { Anthropometric } \\
\text { measurements }\end{array}$} & \multicolumn{6}{|c|}{ Group } \\
\hline & \multicolumn{2}{|c|}{ Placebo (n 194) } & \multicolumn{2}{|c|}{ Zinc (n 198) } & \multicolumn{2}{|c|}{ Zinc plus multivitamins ( $n$ 197) } \\
\hline & Mean & SD & Mean & SD & Mean & SD \\
\hline Birth weight $(\mathrm{g})$ & $2929 \cdot 12$ & $330 \cdot 28$ & $2922 \cdot 22$ & 324.05 & $2938 \cdot 48$ & $317 \cdot 39$ \\
\hline Head circumference $(\mathrm{cm})$ & $34 \cdot 68$ & 0.95 & $34 \cdot 76$ & 0.49 & $34 \cdot 77$ & 0.45 \\
\hline Chest circumference (cm) & 34.63 & $1 \cdot 71$ & 34.73 & 0.82 & 34.77 & 0.84 \\
\hline Arm circumference $(\mathrm{cm})$ & $9 \cdot 43$ & 0.95 & $9 \cdot 51$ & 0.81 & $9 \cdot 44$ & 0.77 \\
\hline \multicolumn{7}{|l|}{$\begin{array}{l}\text { Early neonatal morbidity } \\
\qquad\left(\chi^{2} 94.812(P<0.001)^{\star}\right)\end{array}$} \\
\hline \multicolumn{7}{|l|}{ No morbidity } \\
\hline$n$ & \multicolumn{2}{|c|}{102} & \multicolumn{2}{|c|}{176} & \multicolumn{2}{|c|}{174} \\
\hline$\%$ & \multicolumn{2}{|c|}{$52 \cdot 6$} & \multicolumn{2}{|c|}{88.9} & \multicolumn{2}{|c|}{$88 \cdot 3$} \\
\hline \multicolumn{7}{|l|}{ Infection } \\
\hline$n$ & \multicolumn{2}{|c|}{33} & \multicolumn{2}{|c|}{8} & \multicolumn{2}{|c|}{7} \\
\hline$\%$ & \multicolumn{2}{|c|}{$17 \cdot 0$} & \multicolumn{2}{|c|}{$4 \cdot 0$} & \multicolumn{2}{|c|}{$3 \cdot 60$} \\
\hline \multicolumn{7}{|l|}{ Respiratory distress } \\
\hline$n$ & \multicolumn{2}{|c|}{59} & \multicolumn{2}{|c|}{14} & \multicolumn{2}{|c|}{16} \\
\hline$\%$ & \multicolumn{2}{|c|}{$30 \cdot 4$} & \multicolumn{2}{|c|}{$7 \cdot 1$} & \multicolumn{2}{|c|}{$8 \cdot 1$} \\
\hline \multicolumn{7}{|l|}{ Any morbidity } \\
\hline$n$ & \multicolumn{2}{|c|}{92} & \multicolumn{2}{|c|}{22} & \multicolumn{2}{|c|}{23} \\
\hline$\%$ & \multicolumn{2}{|c|}{$47 \cdot 4$} & \multicolumn{2}{|c|}{$11 \cdot 1$} & & \\
\hline $\mathrm{RR}$ & & & & & & \\
\hline $95 \% \mathrm{Cl}$ & & & & & & \\
\hline ARR & & & & & & \\
\hline $95 \% \mathrm{Cl}$ & & & & & & \\
\hline NNT & & & & & & \\
\hline $95 \% \mathrm{Cl}$ & & & & & & \\
\hline
\end{tabular}

ARR, absolute risk ratio; NNT, numbers needed to treat.

${ }^{*} P<0.05$.

† Three neonates died in the placebo group.

$\mathrm{Zn}$, namely $\mathrm{Zn}$ alone against combined $\mathrm{Zn}$ and multivitamins, on pregnancy outcome. The present study was adequately powered to examine a birth-weight difference of $150 \mathrm{~g}$ between the supplemented and the placebo groups. The findings are consistent with recent systematic reviews in showing that maternal micronutrient supplementation can reduce the risk of pregnancy complications, preterm birth and neonatal infection but not birth weight ${ }^{(22,23)}$.

Women in the present study suffered not only from $\mathrm{Zn}$ deficiency but also from multiple micro- and macronutrient deficiencies ${ }^{(30)}$. This could explain the better outcome parameters in the group that received both $\mathrm{Zn}$ and multivitamins than the group receiving $\mathrm{Zn}$ only. For example, the mean weight gain was relatively higher and the birth weight was higher in the combined multivitamins than the other study groups, although no significant differences in birth weight between the three groups was revealed. This group was also more likely to have normal delivery than the $\mathrm{Zn}$-alone group (RR 0.779, 95\% CI 0.562, $1.081 v$. RR 0.889, 95\% CI $0 \cdot 649,1 \cdot 214)$.

Increased $\mathrm{Zn}$ concentrations after supplementation was reported in some but not in all of the supplementation trials ${ }^{(31)}$. The present study provides further evidence for the effectiveness of $\mathrm{Zn}$ supplementation in improving maternal $\mathrm{Zn}$ status. At follow-up, serum plasma $\mathrm{Zn}$ levels were significantly higher in the supplemented groups than in the placebo group (75.07 (SD 7.44) and 70.35 (SD 7.95) v. $60 \cdot 68$
(SD 9.48) mg, respectively). Also, within each supplemented group, the difference between the first and the second measurement of serum $\mathrm{Zn}$ concentration was significant. We believe that this may be attributed to many factors: compliance with taking the supplements was good; the supplements were consumed between meals to avoid potential competition for absorption; doubling the dose of $\mathrm{Zn}$ substantially increased the daily dietary $\mathrm{Zn}$ intake. The $\mathrm{Zn}$-alone group had lower level at enrolment (58.55 (SD 6.87)) but highest level after supplementation (75.07 (SD 7.44)), which supports the notion that the more deficient cases benefit more from supplementation.

In spite of the significant improvement of $\mathrm{Zn}$ concentration in the supplemented groups in this trial, both supplement modalities had no significant effect either on birth weight or on the other fetal anthropometric measurements. These findings are consistent with the results of recent reviews, meta-analyses and $\operatorname{RCT}^{(10,12,22,32)}$. The bioavailability of $\mathrm{Zn}$ supplement was the main reason suggested to explain the insignificant effect on birth weight reported in supplementation trials. Results of a recently published meta-analysis (Ramakrishnan et $a{ }^{(22)}{ }^{(2)}$ have supported this claim as although a higher dose $(25-62 \mathrm{mg} / \mathrm{d})$ of $\mathrm{Zn}$ was used in five studies out of twelve in this meta-analysis, the effect of $\mathrm{Zn}$ on birth weight was insignificant even after stratification. Absorption of $\mathrm{Zn}$ supplement can be inhibited by Fe and phytate intake, as dietary $\mathrm{Zn}$. Hence, $\mathrm{Zn}$ level adequate to promote birth weight may not 
be achieved after the supplementation of $\mathrm{Zn}^{(33)}$. In the present study, the intake of protein, which is a potent enhancer of $\mathrm{Zn}$ absorption, was low ${ }^{(23)}$ and the weight gain was subnormal. These may partly explain the lack of association between $\mathrm{Zn}$ status and birth weight.

Unlike Zn supplementation, the evidence shows that supplementation with MM has been associated with increase in birth weight and larger micronutrient doses seem to produce greater impact. A meta-analysis of twelve $\mathrm{RCT}^{(21)}$ comparing MM supplementation with $\mathrm{Fe}$-folic acid has reported a small significant increase in the mean birth weight and a reduction in the prevalence of LBW after maternal supplementation with MM in low-income countries. We found a small positive effect of joint supplementation of $\mathrm{Zn}$ and $\mathrm{MM}$ on birth weight of the neonates $(+9 \cdot 4 \mathrm{~g})$, yet this effect was not significant (Table 4). Also, there was no significant effect on the other anthropometric measurements of the neonates in the three groups. The small effect detected by the present trial may be partly explained by the difference in the dose of the MM. Most of the trials in the meta-analysis ${ }^{(21)}$ used the UNIMMAP, which contains the RDA of fifteen vitamins and minerals, while our supplement contains the RDA of five micronutrients only.

Gestational weight gain has been positively associated with fetal growth, and observational studies of food supplementation in pregnancy have reported increases in gestational weight gain and fetal growth ${ }^{(34,35)}$. Results of supplementation trials, however, had been inconsistent ${ }^{(36)}$. The present results indicated that although the total weight gain was significantly higher in supplemented groups, yet there was no significant association between weight gain and birth weight in the three groups. Most of our cases (97.6\%) had subnormal weight gain (below $11.5 \mathrm{~kg}$ according to Institute of Medicine classification), which may explain the absence of an effect of supplementation on birth weight. Weight gains outside the Institute of Medicine's recommended ranges ${ }^{(28)}$ had been associated with twice as many poor pregnancy outcomes than are weight gains within the ranges. In addition, deviations in maternal weight gain can act as useful markers of biological and social factors that relate to poor pregnancy outcome $^{(7,36)}$. The present results were in consistent with these studies where poor women of the placebo group attained the least amount of weight gain and had the poorest outcome.

Although most studies have found no significant overall impact of $\mathrm{Zn}$ supplementation on preterm delivery, some studies $^{(37,38)}$ have found a beneficial impact in selected subgroups of women. A systematic review of twenty RCT including over 15000 women and their babies ${ }^{(10)}$ has found a small but significant reduction in preterm birth and no similar reduction in numbers of LBW. The authors concluded that the evidence for a $14 \%$ relative reduction in preterm birth was primarily represented by trials involving women of low income and living in areas of high perinatal mortality.

Conversely, other systematic reviews and meta-analyses have shown significant benefit of MM supplementation in reducing LBW and small-for-gestational age births compared with the $\mathrm{Fe}$-folate supplements, but no significant effects on the duration of gestation or incidence of preterm birth $^{(10,17-23)}$.

In the present study, there were significantly fewer preterm and stillbirth infants in the supplemented groups compared with the control group ( 1.5 and $3.5 \% v .13 \cdot 1 \%$, respectively). The reduced risk of preterm and stillbirth among the supplemented groups (RR 0.12, 95\% CI 0.036, 0.377 and RR $0 \cdot 27,95 \%$ CI $0.12,0.60)$ is higher than the reduced risk reported by systematic reviews ${ }^{(10,12)}$. Poor maternal health and infection are closely related to preterm birth. Participants in this trial had poor nutritional status at enrolment ${ }^{(30)}$, and they were more likely to benefit from supplementation. Zn alone was more effective than $\mathrm{Zn}$ combined with $\mathrm{MM}$ in averting preterm and stillbirth cases. The effect size achieved by supplementation with $\mathrm{Zn}$ alone was higher than that of joint supplementation with MM. For every nine pregnant women receiving $\mathrm{Zn}$ supplement, one stillbirth/preterm birth would be averted compared with ten cases when combined with MM (Table 3). Prolongation of the time spent in utero was suggested to be the main effect of $\mathrm{Zn}$ in the few studies, which observed increases in average birth weight with $\mathrm{Zn}$ supplementation and not the improvement of fetal growth rate ${ }^{(39)}$.

Second- and third-stage complications - mainly prolonged labour and haemorrhage - were lower in the two supplemented groups than the control group, and the effect was higher in the Zn-alone group (RR 0.43, 95\% CI 0.31, 0.60 for Zn group $v$. RR $0.54,95 \%$ CI $0.40,0.73$ for combined $\mathrm{Zn}$ and $\mathrm{MM}$ group). Results of supplementation trials were variable and even contradictory in some cases. Some trials have reported positive effects ${ }^{(40,41)}$, others no effect $^{(40,41)}$, and in contrast, Dijkhuizen and Wieringa ${ }^{(42)}$ found significantly more deliveries with complications in the group receiving $\mathrm{Zn}(30 \mathrm{mg} / \mathrm{d})$ plus $\mathrm{Fe}$ and folic acid than in the groups receiving $\mathrm{Fe}$ and folic acid alone, $\mathrm{Fe}$ and folic acid plus $\beta$-carotene, or Fe and folic acid plus $\beta$-carotene and $\mathrm{Zn}$.

The differences among these studies may be related to the dose of $\mathrm{Zn}$, the initial $\mathrm{Zn}$ status of the mothers, the co-intake of other micronutrient supplements and obstetric practices ${ }^{(39)}$. It is worth mentioning that in the present trial, data on the occurrence of complications was obtained in post-partum visits and based on women's reports, which may be influenced by subjective judgement and recall bias. It is also worth mentioning that the number needed to treat to avoid one complication was lower ( $n$ 4) when using $\mathrm{Zn}$ alone than when using the combination of $\mathrm{Zn}$ and multivitamin capsules ( $n 5$; Table 3 ). This has an implication on the decision to introduce a new nutrient to the routine ANC programmes as the cost is a key element.

Zn deficiency during pregnancy affects not only the mother but it also has immunological consequences for the fetus. Concurrent deficiencies of MM, many of which function as cofactors or regulatory molecules in immune or inflammatory cascades (e.g. vitamins C, D and Se), increase the adverse effects of $\mathrm{Zn}$ deficiency. Therefore, MM supplements may theoretically augment the effect of $\mathrm{Zn}$ on infectious disease resistance $^{(43)}$. However, Roth et al. ${ }^{(44)}$ in their review found that the evidence for the contribution of MM supplementation to perinatal mortality and neonatal morbidity is limited and the 
evidence base for individual micronutrient effects on neonatal mortality and morbidity is patchy.

In the present trial, early neonatal morbidity - in terms of infections and respiratory distress - was significantly lower in the two supplemented groups compared with the placebo group $(11.1 \%$ and $11.7 v$ v. $47.4 \%$, respectively). The risk reduction resulting from the use of $\mathrm{Zn}$ alone did not greatly differ from that resulting from addition of $\mathrm{MM}$ to $\mathrm{Zn}$ supplementation (77\% (RR 0.23, 95\% CI 0.15, 0.35)) for the $\mathrm{Zn}$ group, and $75 \%$ for the combined group (RR $0 \cdot 25,95 \% \mathrm{CI}$ $0 \cdot 16,0 \cdot 37)$.

For programme managers, the number needed to treat is important before deciding to introduce a new supplement. Of all effects investigated in the present trial, the highest effect size was noticed in aversion of early neonatal infection. For every three pregnant women receiving $\mathrm{Zn}$ or $\mathrm{Zn}$ plus multivitamin supplement, one early neonatal morbidity would be averted.

\section{Limitations of the trial}

Although we controlled many of the factors previously claimed to be responsible for lack of evidence on association between $\mathrm{Zn}$ supplementation and pregnancy outcome; a double-blind design was used, an adequate sample size was recruited to ensure the detection of the smallest worthwhile differences, eligible women were $\mathrm{Zn}$ deficient at enrolment, and full participants were only those with high compliance; yet, the present study has a number of limitations that warrant mention. The dosage of $\mathrm{Zn}$ used in the $\mathrm{Zn}$-alone supplements may be considered low, especially because women's intake of enhancers of $\mathrm{Zn}$ absorption, protein in particular, was very low ${ }^{(23)}$. Some studies that used high doses have revealed positive effect ${ }^{(10,33,35,43)}$. In addition, verifying the occurrence of complications during delivery and postnatal period was based on self-report and not validated clinically, because it was difficult to follow up many deliveries that took place in different hospitals and even in different governorates. Although outcome ascertainment based on maternal recall alone may nullify true effects, we have no particular reason to doubt the validity of these self-reports, because research shows that recalls of obstetric events are highly valid. An additional limitation is that the follow-up extended only for 6 weeks after delivery, which is too short to observe differences in weight gain and morbidity of the newborns.

\section{Conclusion}

Zn supplementation proved to be significantly effective in lowering the risk of second- and third-stage complications, stillbirth and preterm births, and early neonatal morbidity (respiratory tract infection). Supplementation had also positive effects on secondary outcomes such as total weight gain and mean $\mathrm{Zn}$ level. The effect was slightly higher among $\mathrm{Zn}$ supplemented group rather than the combined $\mathrm{Zn}$ and multivitamin group in most outcomes. In contrast, there was no detectable difference in the mean birth weight between the study groups.

\section{Recommendations}

We recommend to include $\mathrm{Zn}$ in the prenatal supplementation programmes for women at risk of Zn deficiency in Egypt. The data on the effect size of the two supplements tested in this RCT should be used when carrying out cost-effective intervention studies for introducing new supplements to the routine ANC programme in Egypt. Nutritional health education should be used as a preventive approach to allow the large sector of the low-income population in our society to maximise the use of the limited resources in the best means. Providing nutritional advice, improving access to micronutrient-rich local foods with reasonable price such as beans (kidney bean), whole-grain cereals (wheat and maize), seeds (sesame), eggs and dairy products, and balanced energy and protein supplements to women during pregnancy may be beneficial. Further studies using various combination and doses of micronutrient supplements in different system settings are recommended.

\section{Supplementary material}

To view supplementary material for this article, please visit http://dx.doi.org/10.1017/S000711451500166X

\section{Acknowledgements}

The authors specially thank the managers and personnel of Smouha and Moharam Bec Maternal and Child Health centres. The guidance provided by Dr Emad Darwish, Professor of Gynecology and Obstetrics, Faculty of medicine, Alexandria University, in the supervision of the clinical aspects of the research is highly appreciated. They also specially thank the Pharo Pharma Company for the preparation of the supplements. The present trial was carried out entirely by the authors and was not financially supported by grants from any organisations.

The authors' contributions are as follows: Samia A. Nossier conceived the idea for the study, supervised the data collection, revised and interpreted the results, and wrote the final manuscript; Noha E. Naeim prepared the study tool, conducted the experiment, searched the references, communicate with the statistician during data analysis and wrote a preliminary draft of the manuscript; Nawal A. El-sayed supervised the collection, managed the nutrition data, prepared the study tools, revised the nutrition-related results and its discussion and critically revised the manuscript; Azza A. Abu-zeid facilitated day-to-day collection of data, supervised the laboratory work and facilitated communication with authorities for permissions and withdrawal of blood samples. All authors read the final draft of the manuscript and approved it.

The authors declare that they have no conflicts of interest.

\section{References}

1. Brown KH, Rivera JA \& Bhutta Z, et al. (2004) Estimated risk of zinc deficiency by country. In: Assessment of the risk of zinc deficiency in populations and options for 
its control: technical document 1 by International Zinc Nutrition Consultative Group (IZiNCG) [Hotz C and Brown KH, editors]. Food Nutr Bull 25, Suppl. 2: Appendix 1: S189S195. http://www.izincg.org/files/izincgtechdocfnb2004.pdf (accessed May 2012).

2. El-Zanaty F \& Way A (2009) Egypt Demographic and Health Survey 2008. Cairo, Egypt: Ministry of Health, El-Zanaty and Associates, and Macro International.

3. Wessells KR \& Brown KH (2012) Estimating the global prevalence of zinc deficiency: results based on zinc availability in national food supplies and the prevalence of stunting. PLOS ONE 7, e50568.

4. Brown KH, Rivera JA \& Bhutta Z, et al. (2004) Overview of Zinc Nutrition. In: Assessment of the risk of zinc deficiency in populations and options for its control: technical document 1 by International Zinc Nutrition Consultative Group (IZiNCG). [Hotz C and Brown KH, editors]. Food Nutr Bull 25, Suppl. 2: Chapter 1: S99-S129.

5. Shah D \& Sachdev HP (2001) Effect of gestational zinc deficiency on pregnancy outcomes: summary of observation studies and zinc supplementation trials. Br J Nutr 85, Suppl. 2, S101-S108.

6. Nriagu J (2011) Zinc deficiency in human health. In Encyclopedia of Environmental Health, pp. 789-800. Available at: http://www.sciencedirect.com/science/article/pii/B9780444 522726006747 and http://www.extranet.elsevier.com/home page_about/mrwd/nvrn/Zinc\%20Deficiency\%20in\%20Hum ans.pdf (accessed May 2012).

7. Deshpande JD, Joshi MM \& Giri PA (2013) Review Article: Zinc: the trace element of major importance in human nutrition and health. Int J Med Sci Public Health 2, 1-6.

8. Karimi A, Bagheri S, Nematy M, et al. (2012) Zinc deficiency in pregnancy and fetal - neonatal outcomes and impact of the supplements on pregnancy outcomes. Iran J Neonatol 3, 77-83.

9. Angelova M, Nedkova V, Nicolov A, et al. (2013) Review: diseases and conditions associated with zinc deficiency: serum zinc in pregnant women with reproductive failures and serum zinc in children with type 1 diabetes. Trakia J Sciences 4, 287-298.

10. Mori R, Ota E \& Middleton P, et al. (2012) Zinc supplementation for improving pregnancy and infant outcome. The Cochrane Database Systematic Reviews, issue 7: CD000230.

11. Gebreselassie SG \& Gashe FE (2011) A systematic review of effect of prenatal zinc supplementation on birthweight: meta-analysis of 17 randomized controlled trials. J Health Popul Nutr 29, 134-140.

12. Chaffee BW \& King JC (2012) Effect of zinc supplementation on pregnancy and infant outcomes: a systematic review. Paediatr Perinat Epidemiol 26, Suppl. 1, 118-137.

13. Hess SY \& King JC (2009) Effects of maternal zinc supplementation on pregnancy and lactation outcomes. Food Nutr Bull 30, Suppl. 1, S60-S78.

14. Darnton-Hill (2013) Zinc supplementation during pregnancy: biological, behavioural and contextual rationale. In WHO-e-Library of Evidence for Nutrition Actions (eLENA). http://www.who.int/elena/bbc/zinc_pregnancy/en/ (accessed June 2012).

15. FAO (2010) Nutrition country profiles, Egypt. Available at: http://www.fao.org/ag/agn/nutrition/egy_en.stm (accessed June 2012).

16. World Bank (2014) Nutrition at a glance: Egypt. http:// siteresources.worldbank.org/NUTRITION/Resources/28184 6-1271963823772/Egypt.pdf (accessed May 2012).

17. Fall CHD, Fisher DJ, Osmond C, et al. (2009) Maternal Micronutrient Supplementation Study Group (MMSSG). Multiple micronutrient supplementation during pregnancy in lowincome countries: a meta-analysis of effects on birth size and length of gestation. Food Nutr Bull 30, S533-S546.

18. Haider BA \& Bhutta ZA (2012) Multiple-micronutrient supplementation for women during pregnancy. The Cochrane Database of Systematic Reviews, issue 11. Art. No: CD004905.

19. Shah PS \& Ohlsson A (2009) Knowledge Synthesis Group on Determinants of Low Birth Weight and Preterm Births. Effects of prenatal multimicronutrient supplementation on pregnancy outcomes: a meta-analysis. CMAJ 180, E99-E108. http://www.cmaj.ca/content/180/12/E99.full.pdf + html?sid= 31113444-cfac-4fb3-b726-59f11cdb3064 (accessed July 2011).

20. Ronsmans C, Fisher DJ, Osmond C, et al. (2009) Maternal Micronutrient Supplementation Study Group. Multiple micronutrient supplementation during pregnancy in lowincome countries: a meta-analysis of effects on stillbirths and on early and late neonatal mortality. Food Nutr Bull 30, Suppl. 4, S547-S555.

21. Bhutta ZA \& Haider BA (2008) Maternal micronutrient deficiencies in developing countries. Lancet 371, 186-187.

22. Ramakrishnan U, Grant F, Goldenberg T, et al. (2012) Effect of multiple micronutrient supplementation on pregnancy and infant outcomes: a systematic review. Paediatr Perinat Epidemiol 26, Suppl. 1, 153-167.

23. Kawai K, Spiegelman D, Shankar AH, et al. (2011) Maternal multiple micronutrient supplementation and pregnancy outcomes in developing countries: meta-analysis and metaregression. Bull World Health Organ 89, 402-411.

24. Zerfu TA \& Ayele HT (2013) Micronutrients and pregnancy; effect of supplementation on pregnancy and pregnancy outcomes: a systematic review. Nutr J 12, 20.

25. Food and Agriculture Organization of the United Nation (FAO) (2001) Zinc. In Human Vitamin and Mineral Requirements. Report of a Joint FAO/WHO Expert Consultation Bangkok, Thailand, Chapter 16, pp. 257-270, Rome, Italy: FAO/WHO. Available at: ftp://ftp.fao.org/docrep/fao/ 004/y2809e/y2809e00.pdf (Accessed 11 June 2014).

26. El-Kassas GM (2004) Levels of some trace elements in pregnant women. M.P.H. Thesis. Alexandria: University of Alexandria, High Institute of Public Health.

27. Nutrition Institute (1996) Food Composition Tables for Egypt. Arab Republic of Egypt (ARE).

28. Yvonne Alexopoulos (2004) Dietary reference intakes. In Krause's Food \& Nutrition therapy, 12th ed., [LK Mahan, S Escott-Stump, JL Raymond and MV Krause, editors]. USA: Elsevier Health Sciences.

29. Institute of Medicine (1990) Subcommittee on nutritional status and weight gain during pregnancy. In Nutrition During Pregnancy, Part I. Weight gain. Washington DC: National Academy Press.

30. Naem N, El-Sayed NM, Nossier SA, et al. (2014) Zinc status and dietary intake of pregnant women, Alexandria, Egypt. J Egypt Public Health Assoc 88, 35-41.

31. Moran VH, Skinner AL, Medina MW, et al. (2012) The relationship between zinc intake and serum/plasma zinc concentration in pregnant and lactating women: a systematic review with dose-response meta-analyses. J Trace Elem Med Biol 26, 74-79.

32. Norrozi M, Borna S, Hanachi P, et al. (2012) Evaluation of zinc supplementation effect on fetal outcomes in pregnant women with lower-than-median serum zinc concentration. J Family Reprod Health 6, 85-89.

33. Hunt IF, Murphy NJ, Cleaver AE, et al. (1989) Zinc supplementation during pregnancy: zinc concentration of serum and hair from low-income women of Mexican descent. Am J Clin Nutr 37, 572-582. 
34. Frederick IO, Williams MA, Sales AE, et al. (2008) Pre-pregnancy body mass index, gestational weight gain, and other maternal characteristics in relation to infant birth weight. Matern Child Health J 12, 557-567.

35. Abrams B, Altman SL \& Pickett KE (2000) Pregnancy weight gain: still controversial. Am J Clin Nutr 71, 1233-1241.

36. Ota E, Tobe-Gai R \& Mori R, et al. (2012) Antenatal dietary advice and supplementation to increase energy and protein intake. The Cochrane Database Systematic Reviews 2012, issue 9: CD000032. Available at: http:// www.ncbi.nlm.nih.gov/pubmed/22972038 (accessed 11 June 2014).

37. Christian P, Khatry SK, Katz J, et al. (2003) Effects of alternative maternal micronutrient supplements on low birth weight in rural Nepal: double blind randomised community trial. BMJ 326, 571-576.

38. Simmer K, Lort-Phillips L, James C, et al. (1991) A doubleblind trial of zinc supplementation in pregnancy. Eur $J$ Clin Nutr 45, 139-144.

39. Caulfield LE, Zavaleta N, Shankar AH, et al. (1998) Potential contribution of maternal zinc supplementation during pregnancy to maternal and child survival. Am J Clin Nutr 68, Suppl. 2, 5499-5508.

40. Mahomed K, James DK, Golding J, et al. (1989) Zinc supplementation during pregnancy: a double blind randomised controlled trial. BMJ 299, 826-830.

41. Jonsson B, Hauge B, Larsen MF, et al. (1996) Zinc supplementation during pregnancy: a double blind randomised controlled trial. Acta Obstet Gynecol Scand 75, 725-729.

42. Dijkhuizen MA \& Wieringa FT (2001) Vitamin A, iron and zinc deficiency in Indonesia: micronutrient interactions and effects of supplementation (Thesis). Wageningen: Wageningen University, p. 200. Available at: http://edepot.wur.nl/ 198975 (accessed 11 June 2014).

43. Maggini S, Wintergerst ES, Beveridge S, et al. (2007) Selected vitamins and trace elements support immune function by strengthening epithelial barriers and cellular and humoral immune responses. Br J Nutr 98, Suppl. 1, S29-S35.

44. Roth DE, Caulfield LE, Ezzati M, et al. (2008) Acute lower respiratory infections in childhood: opportunities for reducing the global burden through nutritional interventions. Bull World Health Organ 86, 356-364. 